\title{
Efficacy of 5-aminosalicylic acid enemas in the treatment of distal ulcerative colitis
}

\author{
MG ROBINSON, MD, FACP, FACG, DL DECKTOR, PHD, FACG
}

\begin{abstract}
The efficacy of $4 \mathrm{~g}$ 5-aminosalicylic acid (5-ASA, mesalamine) enemas was assessed in 666 patients with distal ulcerative colitis. Patients were enrolled in an open-label compassionate use program. One $4 \mathrm{~g}$ 5-ASA enema was administered each night for a period of four weeks and the disease activity index was assessed at baseline and on days 14 and 28 . On days 14 and $28,78.0 \%$ and $88.1 \%$ of patients, respectively, demonstrated an improvement in disease activity Index. The mean decline in disease activity index on day 14 was $40.7 \%$ $(\mathrm{P}=0.0001)$ and on day 28 it was $55.4 \%(\mathrm{P}=0.0001)$. Efficacy was similar whether the disease was confined to or extended beyond $30 \mathrm{~cm}$ from the anus. There was no difference in efficacy in patients suffering their first episode of disease compared to patients suffering subsequent attacks. In conclusion, high dose 5-ASA enemas are a highly effective treatment for distal ulcerative colitis. Can J Gastroenterol 1990;4(7):468-471
\end{abstract}

Key Words: 5-Aminosalicylic acid, Enemas, Topical therapy, Ulcerative colitis

\section{Efficacité des lavements d'acide 5-aminosalicylique dans la colite ulcéreuse distale}

RESUME: L'efficacité des lavements contenant $4 \mathrm{~g}$ d'acide 5 -aminosalicylique (5-ASA) a été évaluée chez 666 patients atteints de colite ulcéreuse. Les patients participaient à un essai ouvert visant la rémission. Un lavement de $4 \mathrm{~g}$ de 5-ASA a été administré chaque jour au coucher pendant quatre semaines et l'indice d'activité de la maladie (DAI) a été relevé au départ, à 14 et à 28 jours. A 14 et à 28 jours, $78 \%$ et $88,1 \%$ des patients, respectivement, manifestaient une amélioration de leur DAI. La baisse moyenne du DAI à 14 jours était de $40,7 \%$ $(\mathrm{P}=0,0001)$ et à 28 jours, elle atteignait $55,4 \%, \mathrm{P}=0,0001)$. L'efficacité était la même, que l'atteinte soit limitée ou qu'elle dépasse $30 \mathrm{~cm}$. On n'a relevé aucune différence d'efficacité entre les patients ayant subi leur première poussée et les malades ayant souffert d'attaques répétées. En conclusion, les lavements à dose élevée $(4 \mathrm{~g} / 60 \mathrm{~g})$ constituent un traitement très efficace de la colite ulcéreuse distale.

Oklahoma Foundation for Digestive Research, Oklahoma City, Oklahoma, USA

Correspondence and reprints: Dr DL Decktor, Oklahoma Foundation for Digestive Research, 711 Stanton L Young Boulevard, Suite 501, Oklahoma City, OK 73104, USA. Telephone (405) $271-4602$
COR THE PAST FOUR DECADES
medical management of ulcerative colitis has generally required the use of corticosteroids or sulphasalazine. Although both treatment options have proved useful, each has its drawbacks. Corticosteroid treatment in enema form or orally administered has been associated with a wide variety of well known side effects such as fluid retention, muscle wasting, osteoporosis, moon facies and acne. Similarly, sulphasalazine has induced allergic reactions and been associated with doselimiting side effects such as nausea, vomiting, headache and malaise.

Sulphasalazine is a conjugate of 5 . aminosalicylic acid (5-ASA, mesalamine) and sulfapyridine. These two components are linked by a diazo-bond that is cleaved by bacterial reductases in the colon. Studies by Azad Khan (1) and others $(2,3)$ have shown that 5 . ASA is the active moiety and that many of the side effects, which have limited the usefulness of sulphasalazine, can be attributed to the 'inactive' sul. pha portion of the molecule.

Topical 5-ASA therapy offers benefits to patients with distal ulcerative colitis by delivering high concentrations of 5-ASA to that area of the colon which will benefit most while maintaining relatively low serum 


\section{TABLE 1}

\section{Disease activity index}

\begin{tabular}{cl} 
Stool frequency \\
0 & Normal \\
1 & Constipation or up to four watery \\
stools per day \\
2 & Five to 10 soft or watery stools per \\
day & Over 10 soft or watery stools per \\
3 & day \\
Rectal bleeding \\
0 & None \\
1 & Streaks of blood \\
2 & Obvious blood \\
3 & Mostly blood \\
Sigmoidoscopic appearance \\
0 & Normal \\
1 & Mild inflammation \\
2 & Moderate inflammation \\
3 & Severe inflammation \\
Physician's assessment of disease \\
severity \\
0 & Normal \\
1 & Mild \\
2 & Moderate \\
3 & Severe \\
\hline
\end{tabular}

levels. Campieri and associates (4) documented homogeneous delivery of drug to the inflamed lower colon, often reaching the splenic flexure following low volume 5-ASA enema administration. Although there was some absorption across the inflamed mucosa, urinary excretion accounted for only $15 \%$ of the administered dose $(5,6)$.

Various relatively small, controlled studies have supported the safety and efficacy of 5-ASA enemas in the treatment of distal ulcerative colitis and proctitis $(7-10)$. The aim of the present study was to evaluate further the efficacy and tolerance of the 5-ASA formulation, Rowasa (Reid-Rowell, Georgia) in a large patient population. The increased size of the study population also permitted a comparative assessment of drug efficacy in patients with disease boundaries less than $30 \mathrm{~cm}$ versus greater than $30 \mathrm{~cm}$ above the anal verge. Similarly, it was possible to assess the effectiveness of 5-ASA enemas for patients exhibiting their first episode versus those with a history of multiple attacks of ulcerative colitis.

\section{PATIENTS AND METHODS}

Patients diagnosed with mild to moderate distal ulcerative colitis were enrolled in a four week, open-label, compassionate use program. Participation required the administration of one $4 \mathrm{~g}$ 5-ASA enema $(60 \mathrm{~mL}$ Rowasa retention enemas containing $4 \mathrm{~g}$ mesalamine in a buffered aqueous solution) each night for four weeks.

The study population was composed of outpatients older than 17 years of age, all of whom had disease involving a minimum of $5 \mathrm{~cm}$ to a maximum of 50 $\mathrm{cm}$ as measured from the anus and confirmed by sigmoidoscopy and biopsy.

Patients were seen at an initial visit and were thereafter assessed on days 14 and 28. At each of these assessments, the disease activity index was measured. The disease activity index (Table 1) represents an attempt to provide objective criteria for assessment of drug efficacy and has been used in previous studies (9). Four variables are assessed: stool frequency, rectal bleeding, sigmoidoscopic appearance of mucosa and physician's assessment of disease severity. Each variable has a range of values for severity with 0 representing no abnormality and 3 representing the most severe disease involvement. As the variables have equal weighting, the overall disease activity index could range from 0 to 12 .

A $t$ test was used to determine if the mean percentage improvement at weeks 2 and 4 was different from baseline. A P value of less than 0.05 was required to indicate a statistically significant improvement. The total number of patients varied between analyses because of missing data for some patients.

\section{RESULTS}

Patient characteristics: Six hundred and eighty-four patients entered the study. Of this population 666 were analyzed, 39 of whom were included despite the fact that they did not meet the selection criteria. Of these 39 patients, 20 exhibited disease extending beyond $50 \mathrm{~cm}, 15$ were diagnosed with Crohn's disease and 14 suffered from colitis of other etiologies. An additional 12 patients were excluded from the analysis because they were younger than 17 years.

Patient population characteristics are presented in Table 2 . The mean age
TABLE 2

\section{Patient characteristics}

\begin{tabular}{ll}
\hline Number of patients & 684 \\
Sex ratio (male:female) & $356: 322$ \\
Extent of disease $(\mathrm{cm})^{*}$ & \\
0 to 20 & 304 \\
21 to 40 & 226 \\
41 to 50 & 84 \\
More than 50 & 20 \\
Duration of disease & \\
Less than one year & 123 \\
One to five years & 190 \\
\hline More than five years & 294 \\
\hline Percentage first episode & 7.2 \\
\hline "Complete data not available &
\end{tabular}

was 40.4 years with a range of 17.3 to 85.8. Most of the patients' $(83.2 \%)$ current episodes had been present for longer than 30 days and most (93.8\%) had suffered prior attacks. In most cases, previous and/or current medical treatment included sulphasalazine (81.8\%), steroid enemas $(76.2 \%)$ and systemic steroids ( $54.8 \%)$.

Efficacy: Several parameters including stool frequency, rectal bleeding, sigmoidoscopic appearance of mucosa and the physician's assessment of disease severity were used to provide a disease activity index and thus assess each patient's response to therapy. In addition, two patient subsets were examined independently: patients with disease extension greater or less than $30 \mathrm{~cm}$; and patients suffering their first episode of inflammatory bowel disease.

The disease activity index was assessed at baseline and weeks 2 and 4 . At week 2 , the mean disease activity index decreased from a baseline of 6.8 to 3.95 , with $78 \%$ of patients demonstrating an improvement. A frequency distribution of change in disease activity index/improvement of disease severity is presented in Figure 1. At week 4, 88.1\% of patients showed improvement, and the mean disease activity index decreased further to a value of 3.04 . The patient disease activity index distribution at week 4 is presented in Fig. ure 2 . Overall, the mean improvement in disease activity index at weeks 2 and 4 was $40.7 \%$ and $55.4 \%$, respectively $(\mathrm{P}<0.001)$.

A summary of the mean values for each of the evaluated parameters is presented in Table 3. Again, the total 


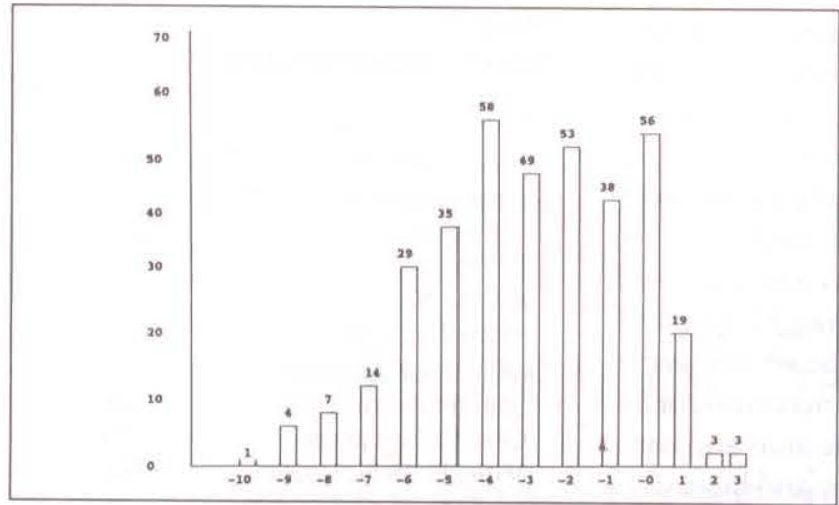

Figure 1) Change in disease activity index at week 2 . A negative number indicates a decrease in disease activity index, ie, an improvement

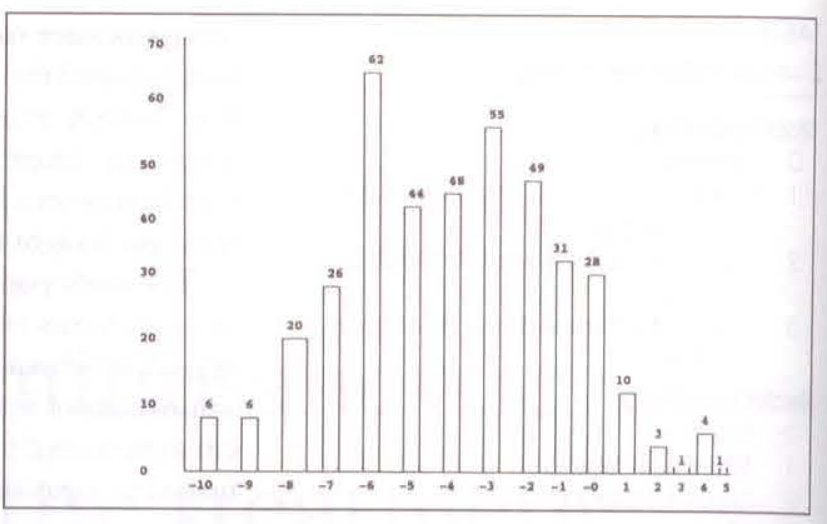

Figure 2) Change in disease activity index at week 4 . A negative number indicates a decrease in disease activity index, ie, an improvement number of patients varies between analyses because of missing data for some patients.

Improvement was noted in each category. Stool frequency decreased as scores improved for 187 of 464 patients $(40.3 \%)$ at week 2 and 215 of 442 $(48.6 \%)$ at week 4 . Rectal bleeding was diminished as scores improved for 292 of 467 patients $(62.5 \%)$ at week 2 and 320 of $450(71.1 \%)$ at week 4 . An improvement in mucosal appearance was noted in 247 of 387 patients $(63.8 \%)$ at week 2 and 319 of 415 $(76.9 \%)$ at week 4 . Finally, the physician's overall assessment indicated improvement for 241 of 443 patients (54.5\%) at week 2 and 308 of $447(70.5 \%)$ at week 4 .

Patients with disease less than or greater than $30 \mathrm{~cm}$ : A comparison of the responsiveness of patients with ulcerative colitis extending less than 30 $\mathrm{cm}$ from the anal verge to those with disease extending beyond $30 \mathrm{~cm}$ revealed no significant difference between the percentage of colitis patients within these groups who responded to 5-ASA enemas. At week 2, 174 of 219 patients $(79.5 \%)$ with disease confined to $30 \mathrm{~cm}$ showed an improvement in disease activity index. By week 4 this percentage had increased to $89.7 \%$ (127 of 145 patients). For patients with disease extending beyond $30 \mathrm{~cm}, 102$ of $137(74.5 \%)$ showed an improvement after two weeks. At week 4, 127 of 145 $(87.6 \%)$ showed improvement.

Although there was no difference in overall patient proportions responding to 5-ASA enemas, the magnitude of response did seem to differ. Patients with disease less than $30 \mathrm{~cm}$ showed a significantly greater reduction in disease activity index $(\mathrm{P}<0.003)$ after two weeks $(44 \%, n=219)$ compared to patients with disease beyond $30 \mathrm{~cm}$ $(33.5 \%, \mathrm{n}=137)$. The statistical significance of these differences disappeared after four weeks, when the improvement increased to $56.8 \%$ and $51.2 \%$, respectively.

First episode versus multi-episode patients: The responsiveness of a small group of first episode patients was also evaluated and compared to that of patients who had experienced more than one episode of ulcerative colitis. Sixty-seven per cent ( 16 of 24 ) of first episode patients showed an improvement in disease activity index at week 2, while $78.7 \%$ ( 270 of 343 ) of multiepisode patients showed improvement. At week 4 the percentage of improved patients increased to $84.6 \%$ ( 22 of 26 ) and $88.3 \%$ (324 of 367 ), respectively, while the differences between groups were diminished. Similarly, there was

\section{TABLE 3}

Mean improvement from baseline in disease activity index

\begin{tabular}{lccccc}
\hline & $\begin{array}{c}\text { Mean at } \\
\text { baseline }\end{array}$ & $\begin{array}{c}\text { Mean at } \\
\text { week 2 }\end{array}$ & $\begin{array}{c}\text { Mean at } \\
\text { week 4 }\end{array}$ & $\begin{array}{c}\text { Mean } \\
\text { change at } \\
\text { week 2 }\end{array}$ & $\begin{array}{c}\text { Mean } \\
\text { change at } \\
\text { week 4 }\end{array}$ \\
\hline $\begin{array}{c}\text { Disease activity } \\
\text { index }\end{array}$ & 6.80 & 3.95 & 3.04 & -2.78 & -3.77 \\
$\begin{array}{c}\text { Stool frequency } \\
\text { Rectal bleeding }\end{array}$ & 1.26 & 0.85 & 0.68 & -0.41 & -0.58 \\
$\begin{array}{c}\text { Mucosal } \\
\text { appearance }\end{array}$ & 1.55 & 0.71 & 0.49 & -0.87 & -1.08 \\
$\begin{array}{c}\text { Physician's } \\
\text { assessment }\end{array}$ & 1.05 & 1.26 & 0.97 & -0.81 & -1.12 \\
\hline
\end{tabular}

no statistically significant difference in mean percentage improvement in disease activity index for patients suffering their first attack compared to patients with more than one episode.

5-ASA enemas were generally well tolerated. The most common adverse reactions recorded were abdominal pain $(8.1 \%)$, headaches $(6.5 \%)$ and flatulence $(6.1 \%)$.

\section{DISCUSSION}

Patients included in this study were enrolled on a compassionate use basis. Therefore the study was open-label and nonrandomized. However, an extreme. ly large patient population was assessed. These results clearly support $4 \mathrm{~g} 5$-ASA enemas as effective treatment of distal ulcerative colitis and are consistent with results of smaller, placebo controlled, double-blind studies $(7,9)$.

Patients improved in all four categories which comprise the disease activity index: stool frequency, rectal bleeding, sigmoidoscopic appearance of mucosa and physician's assessment of 
disease severity. The greatest mean improvement from baseline was observed in mucosal appearance. This is consistent with studies by Powell-Tuck et al (11), which suggest that mucosal appearance correlates best with several other measures of disease activity.

Efficacy improved with continued treatment. At week 2, 78\% of patients exhibited improvement in their disease activity indices, and mean disease activity index declined $40.7 \%$. At week 4 , $88.1 \%$ of patients exhibited improvement in their disease activity indices and mean disease activity index declined 55\%.

Comparing the 5-ASA response to

\section{REFERENCES}

1. Azad Khan KA, Piris J, Truelove SC. An experiment to determine the active therapeutic moiety of sulphasalazine. Lancet 1977;ii:892-5.

2. Dew MJ, Ryder RKJ, Evans BK, Rhodes J. Colonic release of 5-aminosalicylic acid from an oral preparation in active ulcerative colitis. $\mathrm{Br} \mathrm{J}$ Clin Pharmacol 1983;16:185-7.

3. Dew MJ, Cardwill M, Kidwai NS, Evans BK, Rhodes J. 5-aminosalicylic acid in serum and urine after administration by enema to patients with colitis. J Pharmacol 1983;35:323-4.

4. Campieri M, Lanfranchi GA, Brignola C, et al. Retrograde spread 5-aminosalicylic acid enemas in patients with acute ulcerative colitis. Dis Colon the extent of disease at two weeks, there appeared to be a significantly greater early improvement in patients with disease confined to less than 30 $\mathrm{cm}$. However, this difference was not significant at four weeks. These data suggest that patients with more limited disease may respond more quickly. Ultimately, however, patients with left-sided disease exhibited no difference in response whether the boundary of disease was less than or greater than $30 \mathrm{~cm}$.

Finally, the size of this open-label study allowed assessment of a small but distinct patient subgroup experiencing their first episode of ulcerative colitis.

Rectum 1986;29:108.

5. Campieri M, Lanfranchi GA, Boschi S, et al. Absorption of rectally administered 5-ASA in patients with ulcerative colitis. Gastroenterology 1984:86:1039.

6. Campieri M, Lanfranchi GA, Boschi S, et al. Topical administration of 5 aminosalicylic acid enemas in patients with ulcerative colitis. Studies on rectal absorption and excretion. Gut 1985;26:400-5.

7. Campieri M, Gionchetti P, Belluzzi A, et al. Efficacy of 5-aminosalicylic acid enemas versus hydrocortisone enemas in ulcerative colitis. Dig Dis Sci 1987;32:67S-70S.

8. McPhee MS, Swan JT, Biddle WL, Greenburger NJ. Proctocolitis
These patients did not respond to 5 ASA enemas in a significantly different manner than patients who have suffered from multiple episodes.

In conclusion, 5-ASA enemas are a highly effective and well tolerated treatment for distal ulcerative colitis. Excellent responses in acute left-sided colitis as well as chronic recurrent disease were observed.

ACKNOWLEDGEMENTS: The authors acknowledge the technical support and assistance of Lowell Bergen, $\mathrm{PhD}$ and David Rothbart, MD of Reid-Rowell Laboratories in Marietta, Georgia, USA.

unresponsive to conventional therapy: Response to 5-ASA enemas. Dig Dis Sci 1987;32:76S-81S.

9. Sutherland LR, Martin F, Greer S, et al. 5-aminosalicylic acid enema in the treatment of distal ulcerative colitis, proctosigmoiditis and proctitis. Gastroenterology 1987;92;1894-8.

10. Guarino J, Chatzinoff M, Berk T, Friedman LS. 5-aminosalicylic acid enemas in refractory distal ulcerative colitis: Long-term results. Am ] Gastroenterol 1987;82:732-7.

11. Powell-Tuck J, Day DW, Buckell NA, Wadsworth J, Lennard-Jones JE. Correlations between defined sigmoidoscopic appearances and other measures of disease activity in ulcerative colitis. Dig Dis Sci 1982;27:533-7. 


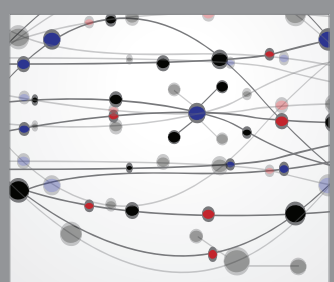

The Scientific World Journal
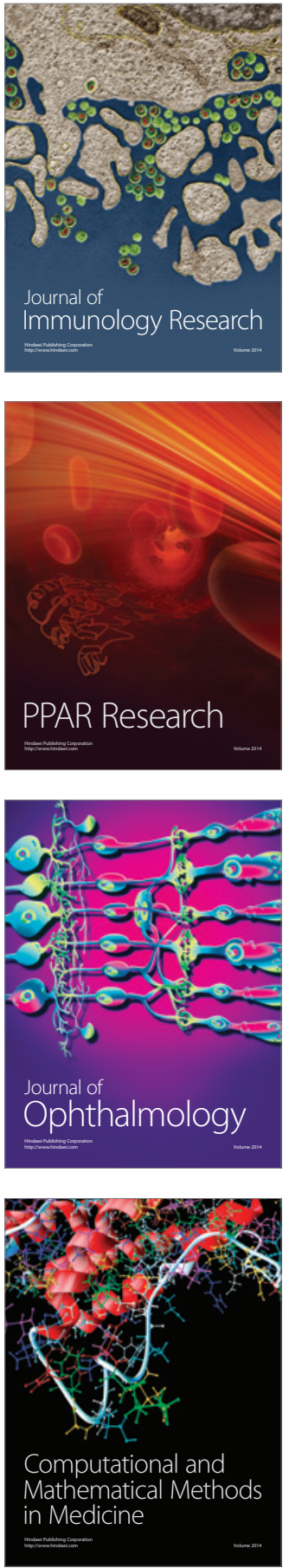

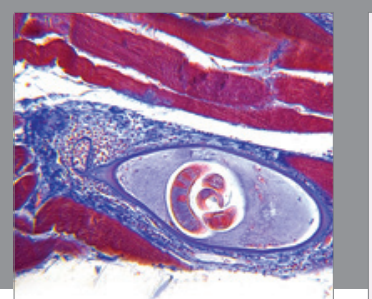

Gastroenterology Research and Practice

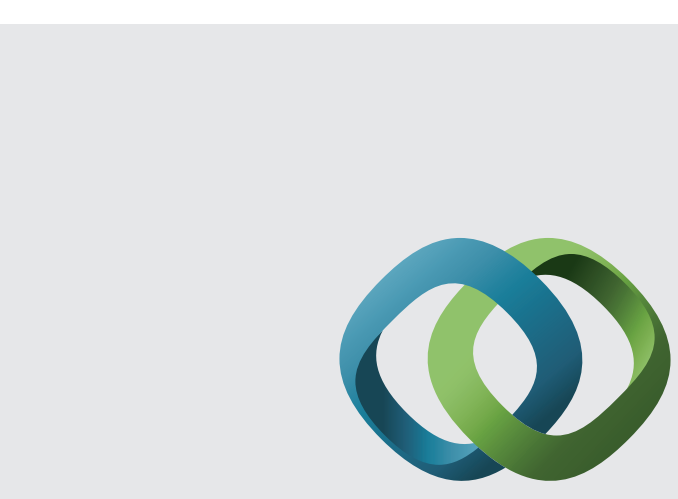

\section{Hindawi}

Submit your manuscripts at

http://www.hindawi.com
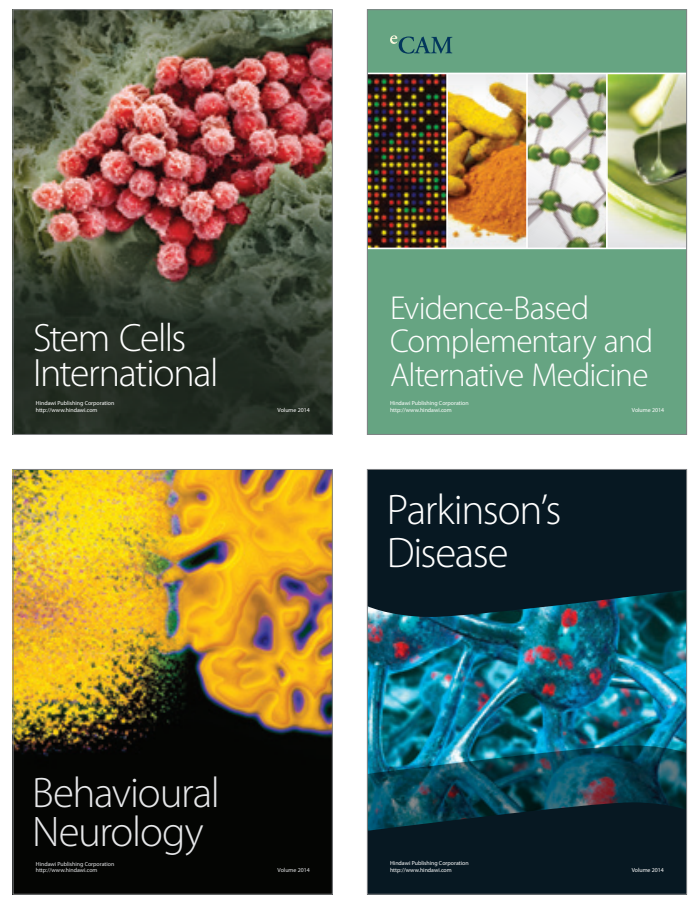
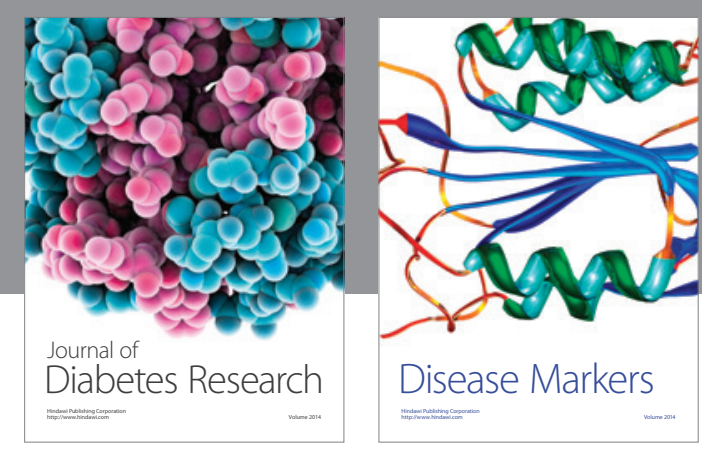

Disease Markers
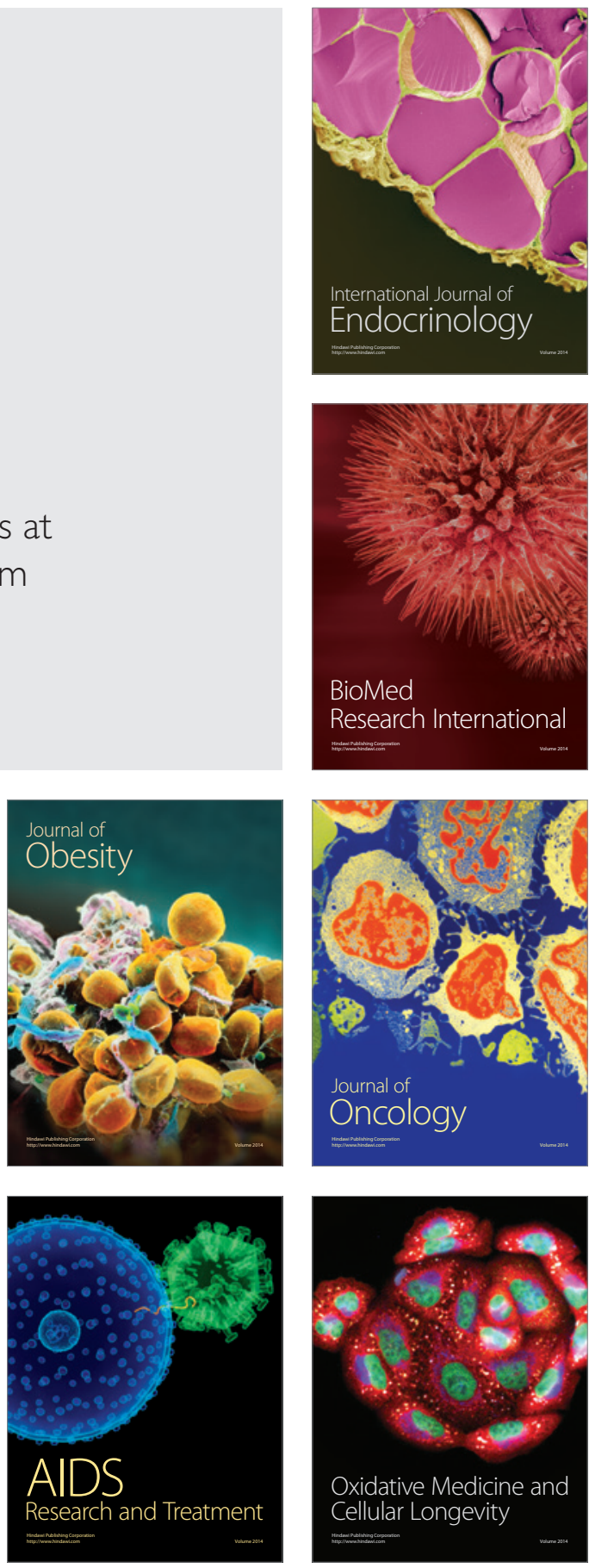